\title{
FORMATION OF FAILURE MODELS FOR THE EVALUATION OF THE RELIABILITY OF SUPPLY CHAINS
}

\author{
Valery Lukinskiy ${ }^{1}$, Vladislav Lukinskiy ${ }^{2}$ \\ ${ }^{I}$ National Research University Higher School of Economics \\ St. Petersburg, Russia, 16 Soyuza Pechatnikov ulitsa \\ Phone: 007(812)7466623,e-mail: vslukinskiy@hse.ru \\ ${ }^{2}$ National Research University Higher School of Economics \\ St. Petersburg, Russia, 16 Soyuza Pechatnikov ulitsa \\ Phone:007(812)7466623,e-mail: vvlukinskiy@hse.ru
}

\begin{abstract}
Logistics and supply chain management is a comparatively new scientific field which has been rapidly developing.
Apart from the criterion of total logistics costs, that is used to evaluate the efficiency of supply chains, another criterion total satisfaction of consumer needs - is being increasingly used for the same purpose. It can be explained by the transition to such new logistics concept as the sustainability of supply chains, which is characterized not only by flexibility, rate of response, strength, adaptability, but mostly by the reliability of functioning of the logistics system's elements.

The paper presents critical analysis of the existing approaches to the formation of failure models in supply chains, the methodical approach and classification of failures for the key logistics functions (purchasing, order processing, transportation, storage, warehousing and materials handling) as well as some developed and improved failure models for a number of logistics functions and operations; there have been also given some examples of calculating the reliability indices for the elements of the supply chain.
\end{abstract}

Keywords: supply chains, reliability, failures, calculation models

\section{Introduction}

The modern period of logistics development is characterized by a heightened interest in the reliability of supply chains. The aim of researches in this direction is creation of a complex of models and methods by means of which it would be possible to optimize the supply chains with the account of the reliability indices.

But the peculiarity of the situation is the fact that this stage of development of the theory of logistics and supply chain management is associated with the emergence of new concepts such as "sustainability", "durability", "«robustness", "flexibility", "adaptability", "response time" and, of course, "reliability". Thus, in the paper (Sergeev, 2013), on the basis of the shift of logistical paradigms, the authors conclude that "durability has become one of the most important parameters of the supply chain operation along with the level of service and costs", "and, namely, durability serves as the criterion of the efficiency of the whole supply chain". However, we think that the cited paper involves some uncertainty in the interpretation of the concepts of "durability" and "reliability". For example, in the section, which is concerned with "the durability and reliability of technical systems", both concepts are based on the same principles and the difference between them is the following:

- reliability is a property of the system to maintain its characteristics of the key performance indicators (KPI) within the established values;

- durability is a property of the system to restore itself that means that "the system is able to restore the values of the KPI in the specified tolerances".

Provided that the objects of the theory of reliability are restorable objects, for which the recovery of a serviceable state is stipulated in the relevant documentation, it appears that the distinction between the two terms is virtually blurred. However, in the course of developing of the table of distinctive characteristics, "sustainability" and "durability" were attributed by the authors to higher levels - to the zero and the first level correspondingly, whereas "reliability" was attributed to the lower third level.

For almost all the above-mentioned concepts, there are no indicators (except the KPI system in the SCOR-model) and methods for their evaluation. Therefore, we believe that the reliability theory of technical systems, as well as its accumulated analytical and application developments, with the account of the specific character of the supply chain functioning, can be chosen as a real platform for their formation. 
The performed analysis of a number of sources has shown that, despite the existence of separate decisions, the bulk of the problems of assessing the reliability of supply chains are far from the final decision for the following reasons:

1. Supply chains are considered as systems that are operating to the first failure, while the probability of no-failure operation is accepted as the main indicator of the reliability of supply chains (Blanchard, 2004; Zaitzev and Uvarov, 2012).

2. The calculations on the proposed models and methods are being made on the basis of the original data, while collection, analysis and systematization are reduced to simple statistical dependencies (Sergeev, 2013); for example, "the perfect order" is defined as the ratio of "the number of precisely executed orders" to "the total number of orders".

3. The number of variations of simple failure models is limited and reduced to three types:

- The model of the "perfect" or the "ideal" order (Ballou, 1999; Christopher, 2004);

- The model of "supply and demand" (Wolfgang and Thorsten, 2006), which is formed by the analogy to the "load-strength" technical systems (Gertsbakh and Kordonsky, 1966);

- The «just-in-time» model (Lukinskiy et.al. 2012).

4. The description of complicated failure models, involving multiple logistic operations, has not been possible to find in the sources available to the reviewers.

5. The main tool for improving the reliability of supply chains is considered external (or excess) redundancy, while internal sources, in particular, insurance reserves, are not given the necessary attention (Lukinskiy et.al., 2014).

\section{Classification of the features of failure models in supply chains}

For the development of a methodological approach to the classification of failure models, it is reasonable to clarify the basic concepts and definitions that form the conceptual framework of the reliability of supply chains.

The analysis of a number of sources has shown that the concept of "failure" has a fairly wide range. Therefore, in this paper we choose a synthesized version of "failure" as "the loss of the ability of the whole supply chain, as well as of the links in the chain, to perform its functions in accordance with the agreements between the members of the chain".

It should be emphasized that in the works on reliability, except the notion of "failure", one can find such terms as "defect", "damage", "problem" and "malfunction" which sometimes are used interchangeably that, in our opinion, is incorrect. The most important of these terms is "malfunction", which can be characterized as a transient failure leading to a short-term partial loss of functioning that can be corrected by the operator without significant time and cost.

For the specification of the general approach, we will consider the kinds of failures concerning the main and the related logistics flows.

Material flow includes components related to the physical parameters of the order (for example, the number, nomenclature, weight and others). Examples of failures related to material flow are damage of packages, deficiency in quantity, re-sorting, insufficient amount dispatched, etc.

Information flow includes document flow and information sharing occurring within the supply chain during its operation. Failures may be associated with the execution or handling of documents in the supply chain or in the process of information exchange between supply chain members.

Financial flow is characterized by monetary costs for the organization of delivery orders in the supply chain. Occurring failures are associated with additional costs for the organization of cargo delivery. These costs may occur in the process of recovery after a failure or as a consequence of any failure (for example, penalties for exceeding the allowable cargo weight or penalties for lateness).

Intellectual flow reflects the influence of the human factor. Despite the controversial nature of this concept, we believe that consideration of the impact of staff is relevant, but so far researchers have not paid enough attention to this factor, despite the fact that it is involved in the performance of all types of logistics operations and functions in the supply chain.

In addition to the mentioned failures, in all flows various kinds of extreme emergency situations, which are advisable to segregate to a separate category, can occur. It refers to situations caused by natural disasters, force majeure and other reasons which cannot be influenced by the supply chain participants.

Thus, the supply chain is a complex system which has independent functionality and consists of many interacting components (subsystems), thereby acquiring new properties that cannot be reduced to the properties of the subsystem level. 
The supply chain is a system of «man-machine-environment», where the environment means the totality of social and economic environments. Obviously, in the supply chain one should allocate units (members of the supply chain) and elements (executable operations). Such decomposition, which separates companies and the operations they perform within a specific supply chain, allows evaluating any supply chains.

We should also note such property as self-organization (and self-training) of a supply chain, which is goal-directed behavior in complex environments through adequate changes in both internal and external conditions for the recovery of the operation.

Table 1. Classification of criteria of failure models in supply chains

\begin{tabular}{|l|l|}
\hline Criterion & Classification \\
\hline Type of logistics flow & Material, information, financial, service, intellectual (human factor), etc. \\
\hline Consideration of failure occurrence & $\begin{array}{l}\text { Without considering time (statistical) } \\
\text { Taking into account time (dynamical) }\end{array}$ \\
\hline Character of variables (arguments) & $\begin{array}{l}\text { Stochastic events, stochastic variables } \\
\text { Stochastic processes (flows) }\end{array}$ \\
\hline Relationship between the variables & $\begin{array}{l}\text { Independent } \\
\text { Dependent (functional, stochastical) }\end{array}$ \\
\hline The relationship between operations & $\begin{array}{l}\text { Simple (one-parameter) } \\
\text { Complicated (multi-parameter) } \\
\text { Combined }\end{array}$ \\
\hline
\end{tabular}

Generalization of different sources, dedicated to researches of the reliability of logistics systems, allows us to classify the main criteria of failure models in the supply chain (see table 1). Obviously, the criteria listed in the table do not represent all the possible options, but at the same time they make it possible to characterize a large number of them, which is particularly important for the complicated and combined models involving different types of processes, the types of relationship between the variables, their character and others.

\section{Failure models of the main logistics functions and operations}

Table 2 shows the basic failure model for a number of logistic functions and operations. The presented models are based on the general theory of reliability of complex systems (Gertsbakh and Kordonsky, 1966; Lukinskiy et.al., 2012) and the disciplines that are included in the operations research (probability theory, the theory of stochastic processes, queuing theory, the theory of recovery, etc.), in particular, on the theorem on numerical characteristics, repeated experiments, the compositions of distributions, the transformation of random variables, etc. (Wentzel, 1969).

Table 2. Failure models in supply chains

\begin{tabular}{|c|c|c|}
\hline Logistical function & Logistical operation & $\begin{array}{l}\text { Model for calculation of reliability indices (similar } \\
\text { model) }\end{array}$ \\
\hline \multirow[t]{3}{*}{$\begin{array}{l}\text { 1. Procurement, } \\
\text { orders management }\end{array}$} & $\begin{array}{l}\text { Forecasting of supply and demand } \\
\text { volumes }\end{array}$ & $\begin{array}{l}\text { The task of «demand - offer» (similar to task of «load - } \\
\text { strength») }\end{array}$ \\
\hline & Determination of order quantity & $\begin{array}{l}\text { Static problem - one-time purchase (analogous to «economic } \\
\text { risk») }\end{array}$ \\
\hline & $\begin{array}{l}\text { The choice of the intermediary } \\
\text { (suppliers, carriers, etc.) }\end{array}$ & $\begin{array}{l}\text { Reliability of redundant systems (similar to «hot», «cold» } \\
\text { and «easier» redundancy and etc.) }\end{array}$ \\
\hline \multirow[t]{2}{*}{$\begin{array}{l}\text { 2. Warehousing, } \\
\text { materials handling }\end{array}$} & Formation of the perfect (ideal) order & $\begin{array}{l}\text { Simple probabilistic models for separate indicators. } \\
\text { Combined models }\end{array}$ \\
\hline & Order picking & $\begin{array}{l}\text { A probabilistic model that is based on the composition of } \\
\text { stochastic variables (analogous to «just in time» model) }\end{array}$ \\
\hline 3. Transportation & $\begin{array}{l}\text { Transportation (multimodal, unimodal } \\
\text { and etc.), delivery }\end{array}$ & The «just-in-time» model. Reliability of redundant systems \\
\hline \multirow{2}{*}{$\begin{array}{l}\text { 4. Inventory } \\
\text { management }\end{array}$} & Determination of inventory parameters & Probabilistic estimates of values of safety stock and deficit \\
\hline & $\begin{array}{l}\text { Selection of inventory management } \\
\text { strategy }\end{array}$ & $\begin{array}{l}\text { Models based on the achievement the limiting values of } \\
\text { implementations of inventory consumption (similar to } \\
\text { «calculations for wear») }\end{array}$ \\
\hline $\begin{array}{l}\text { 5.Supply Chain } \\
\text { Management }\end{array}$ & $\begin{array}{l}\text { Estimation of influence of reliability } \\
\text { indices of individual operations on the } \\
\text { efficiency of the supply chains (simple, } \\
\text { multi-level, etc.) }\end{array}$ & Discrete-continuous models for restorable logistics systems \\
\hline
\end{tabular}


Let us consider failure models (see table 2), focusing attention on their clarification and correction.

Model of «supply and demand». The density of distribution of the sum of two random variables $z=x+y$, when the random variables are independent, is expressed by one of the formulas (Wentzel, 1969).

$f(z)=\int_{-\infty}^{\infty} f_{1}(x) f_{2}(z-x) d x$

or

$$
f(z)=\int_{-\infty}^{\infty} f_{1}(z-y) f_{2}(y) d y .
$$

The density of distribution $f(z)$ is called the composition of distribution laws of summands $f_{1}(x)$ and $f_{2}(y)$.

In describing the logistics processes of procurement and the management of orders with stochastic values of demand $y$ (consumer) and supply $x$ (supplier), it is necessary to consider the difference between the random variables $x$ and $y$, i.e. $z=x-y=x+(-y)$. In this case, the formula (1) and (2) are written in the form:

$$
f(z)=\int_{-\infty}^{\infty} f_{1}(x) f_{2}(x-z) d x=\int_{-\infty}^{\infty} f_{1}(y-z) f_{2}(y) d y .
$$

The corresponding probability of customer satisfaction (the lack of deficit) is defined by the dependence:

$$
F(z)=\int_{0}^{z} f(z) d z
$$

The numerical method of calculation of $f(z)$ and $F(z)$ is the most common, but for some distribution functions there can be obtained analytical solutions (see table 3).

Table 3. Formulas for calculating the probability of the demand satisfaction (the model of «supply and demand»)

\begin{tabular}{|l|l|l|}
\hline \multicolumn{2}{|c|}{ Distribution laws; the parameters of the law } & \multicolumn{1}{c|}{ Calculating formula } \\
\cline { 1 - 2 } $\begin{array}{l}\text { Nomand } \\
\text { average value } M_{y} ; \text { Root-mean- } \\
\text { square deviation } \sigma_{y}\end{array}$ & $\begin{array}{l}\text { Normal; } \\
\text { average value } M_{X} ; \text { Root-mean- } \\
\text { square deviation } \sigma_{X}\end{array}$ & $P=1-F\left(-\frac{M_{x}-M_{y}}{\sqrt{\sigma_{x}^{2}+\sigma_{y}^{2}}}\right)$ \\
\hline Exponential; parameter $\lambda_{y}$ & $\begin{array}{l}\text { Exponential (with the shift } \\
\left.\text { parameter } x_{C}\right) ; \text { parameter - } \lambda_{x}\end{array}$ & $P=1-\frac{\lambda_{x}}{\lambda_{x}+\lambda_{y}} \exp \left(-\lambda_{x} x_{C}\right)$ \\
\hline Poisson; b & Poisson; a & $\begin{array}{l}P(z=k)=\sum_{m=0}^{\infty} \frac{b^{m}}{m !} \cdot \frac{a^{m+k}}{(m+k) !} e^{-(a+b)} \\
\text { for positive values } k>0\end{array}$ \\
\hline
\end{tabular}

The model of "determination of order quantity" is based on the well-known static (or oneperiodic) inventory management task. The most common version of the model can be written as

$$
C_{\Sigma}=C(s-z)+h \int_{0}^{S}(s-x) f(x) d x+p \int_{S}^{\infty}(x-s) f(x) d x
$$

where $\mathrm{c}$ - the purchase price (or production) per unit of output;

$\mathrm{s}$ - size of the order;

$\mathrm{z}$ - initial stock (before ordering);

$\mathrm{h}$ - specific costs associated with the storage of surplus;

$\mathrm{x}$ - random variable of demand for the product with the distribution density;

$\mathrm{p}$ - specific losses from missed demand. 
From the condition $\left(d C_{\Sigma} / d s\right)=0$ after transformations we find the so-called "critical ratio"

$F(s)=\frac{p-c}{p+h}$,

where $\mathrm{F}(\mathrm{s})$ - cumulative distribution function of demand.

From the point of view of estimating the reliability of the supply chain, this model allows us to calculate the probability of the non-selling production batch or deficit probability $\mathrm{P}(\mathrm{s})=1-\mathrm{F}$ (s).

It should be emphasized that the "critical ratio" depends only on the cost parameters. Thus, the size of the order $\mathrm{S}$ will be determined by the distribution function $\mathrm{F}$ (s) chosen to approximate the demand.

Table 4 shows the formulas for determining $\mathrm{S}$ and the results of comparative calculations for some distribution laws. As the input data, the following parameters were taken: $\mathrm{p}=10 ; \mathrm{c}=6 ; \mathrm{h}=1$; the average value of demand $\bar{x}=10$; root-mean-square deviation $\sigma_{x}=4$.

Table 4. The optimum size of the order at a one-time purchase

\begin{tabular}{|c|c|c|c|}
\hline The distribution law & The parameters of the law & The optimum size of the order $S$ & The results of calculation \\
\hline Normal & $\bar{x}=10 ; \sigma_{x}=4$ & $F\left(\frac{s-\bar{x}}{\sigma}\right)=\frac{p-c}{p+h}$ & $\mathrm{~S}=8,6$ \\
\hline Exponential & $\lambda=\frac{1}{\bar{x}}$ & $S=\frac{1}{\lambda} \ln \frac{p+h}{c+h}$ & $\mathrm{~S}=4,5$ \\
\hline Weibull & $m=f(v) ; x_{0}=\frac{\bar{x}}{b_{m}}$ & $S=x_{0} \sqrt[m]{\ln \frac{p+h}{c+h}}$ & $\mathrm{~S}=8,4$ \\
\hline Rayleigh & $M=\frac{\bar{x}}{\sqrt{0,5 \pi}}$ & $S=M \sqrt{2 \ln \frac{p+h}{c+h}}$ & $\mathrm{~S}=7,6$ \\
\hline Uniform & $a=\bar{x} ; b=\sigma \sqrt{3}$ & $S=\frac{p-c}{p+h}(b-a)+a$ & $\mathrm{~S}=8,9$ \\
\hline
\end{tabular}

Model of «selection of intermediary». The model is based on classic dependencies of the socalled circuit reliability when the redundant elements are included in the system «in parallel» to those elements, which reliability is insufficient. For example, to assess the reliability of the supply chain link, which includes one main and «n» redundant suppliers, the probability of no-failure operation is calculated by the formula

$$
P=1-\left(1-P_{0}\right)\left(1-\prod_{i=1}^{R}\left(1-P_{i}\right)\right),
$$

where $\mathrm{P}_{\mathrm{o}}, \mathrm{P}_{\mathrm{i}}$ - the probabilities of no-failure operation of one main and «n» redundant suppliers, respectively.

As a rule, this kind of models is complemented by the condition, associated with limiting the costs for the system operation.

Model of «perfect (ideal) order». This model is most common in the works related to the reliability of supply chains. Usually, the calculated dependence includes three criteria of failure: fulfillment of an order out-of-time (P1), number of orders that are fulfilled not to the fullest extent (P2) and the number of improperly executed documents (P3).

The calculation formula of the probability of failure of formation of a perfect order has the form

$$
P_{0}=\prod_{i=1}^{n} P_{i}=P_{1} P_{2} P_{3}
$$

The number of elements in the calculation formula varies within wide limits, for example, in (Ballou, 2004) $n=5$. Also, when forming a multiproduct order, it is recommended to use the formula for WAFR (weighted average fill rate) 
$P_{0}=\sum \omega_{i} P_{i}$,

where $\mathrm{w}_{\mathrm{i}}$ - frequency (weighting coefficient) for $\mathrm{i}^{\text {th }}$ nomenclature;

$\mathrm{P}_{\mathrm{i}}-$ the probability of failure-free formation of the $\mathrm{i}^{\text {th }}$ nomenclature of an order.

However, the validity of using (9) requires further proof, since the method for determining weighting coefficients $\mathrm{w}_{\mathrm{i}}$ is subjective.

Possible approach for the assessment of perfect order can be formed on the basis of the theorem on repeated experiments (Wentzel, 1969). According to this theorem

$$
\prod_{i=1}^{n}\left(q_{i}+p_{i} z\right)=\sum_{m=0}^{n} P_{m, n} z^{m}
$$

where $p_{i}$ - the probability of occurrence of event $\mathrm{A}$ in the $\mathrm{i}^{\text {th }}$ experiment;

$P_{m, n}$ - the probability of occurrence of event $\mathrm{A}$ in the $\mathrm{n}$ experiments precisely $\mathrm{m}$ times;

$z$ - arbitrary parameter.

After expanding the left-hand side of the equation (10) and the reduction of similar terms for different $z^{m}$, it becomes possible to find the probability $P_{0, n}, P_{1, n}, \ldots, P_{m, n}$, i.e. the probability of formation of a perfect order with a different number of simultaneously observed features of failure, $\mathrm{m}$

The next step is the approximation of the obtained dependence $P_{m, n}$ by one of the discrete distributions, such as a binomial one:

$$
P_{m, n}^{*}=C_{n}^{m} p^{m} q^{n-m}=\frac{n !}{m !(n-m) !} p^{m} q^{n-m},
$$

where $p$ - the average value of probability of faultless formation of a perfect order; $q=1-p$. For the calculation $p$ we can use formula $p=\sum_{i=1}^{m} p_{i} / m$.

Example. According to the results of the observations, the following features of failures have been identified: non-compliance with the application in time (probability of no-failure perform the operation $\left.p_{1}=0,9\right)$; the number of orders is not in full $\left(p_{2}=0,8\right)$; the number of misfiled documents, $p_{3}=0,5$. The average value for the binomial distribution will be $p=0,733$. Assume that $\mathrm{n}-$ the total number of the features of imperfect order; $\mathrm{m}$ - the simultaneous appearance of $0,1, \ldots \mathrm{n}$ features.

Table 5 shows the results of calculating the probabilities of formation of a perfect order by the formula (10) and (11). From the analysis of the table we can say that between the distributions there is considered a good consensus.

Table 5. The results of calculation of probabilities $P_{m, n}$ and $P_{m, n}^{*}$

\begin{tabular}{|c|c|c|}
\hline \multirow{2}{*}{ Number of features of failure, $\mathbf{m}$} & \multicolumn{2}{|c|}{ The results of calculation of probabilities based on } \\
\cline { 2 - 3 } & theorem on repeated experiments & binomial distribution \\
\hline 0 & 0,360 & 0,393 \\
\hline 1 & 0,490 & 0,430 \\
\hline 2 & 0,140 & 0,157 \\
\hline 3 & 0,010 & 0,020 \\
\hline
\end{tabular}

The «just-in-time» (JIT) model.

Transportation is a key logistical operation, a description of which is characterized by a large number of indicators and factors. As mentioned previously, the most complex in the preparation and decision-making in the supply chain management are transportation operations. This is due to the fact that the external environment of these operations is characterized by the uncertainty, which in turn is associated with a variety of risks that differ in frequency and in nature. The main classification criteria of transportation include modes of transport (road, sea, etc.) and the type of transportation (direct, combined, unimodal, multimodal, etc.). 
Time characteristic of overcoming complicated circumstances and observing the requirements of international road transport (IRT) are random and should be taken into account while designing delivery of cargo, planning and arranging freight transportation just in time.

Taking the above mentioned features into account, the total time of transportation can be determined by means of formula:

$T_{o}=\sum_{i=1}^{A} t_{i, i+1}+\sum_{j=1}^{B} \tau_{j}+\sum_{k=1}^{C} \Theta_{k}$,

where $t_{i, i+1}$ - travelling time between $i$ and $(i+1)$ points; $\tau_{j}$ - time of preparation of customs documents in $\mathrm{j}$ - point (in the country and at the borders); $\Theta_{k}$ - time for loading, unloading and warehousing in $k$-point; $A, B, C$ - the number of sections of the roads a car moves, customhouses and loading/unloading points.

Then, with the account of the peculiarities of the international transportation, the formula of calculation of the total time spent on the route should be adjusted and presented as follows:

$T_{o}=\sum_{i=1}^{A} t_{i, i+1}+\sum_{j=1}^{B} \tau_{j}+\sum_{k=1}^{C} \Theta_{k}+\sum_{l=1}^{D} \varphi_{l}+\sum_{m=1}^{E} \psi_{m}+\sum_{n=1}^{F} \eta_{n}$,

where $\varphi_{l}$ - random component, showing the increase of the trip time for repair and maintenance activities and other reasons; $\psi_{m}$ - random component reflecting constraints connected with AETR; $\eta_{n}$ - random component reflecting bans on the use of heavy-load vehicles; $D, E, F$ - the number of cases of standing idle (considering the mentioned reasons).

JIT is one of the concepts of logistics, which, according to SCOR, is a model corresponding to the indicator «duration cycle of order fulfillment». In the paper (Lukinskiy et al, 2012), the JIT model is formed on the basis of the composition of distribution laws of stochastic variables $\mathrm{T}_{\mathrm{i}}$, which are the time of execution of $i^{\text {th }}$ operation. The probability $\mathrm{P}$ of the just-in-time logistic cycle execution can be calculated with the formula

$$
P=\Phi\left(\frac{T_{o}-T_{c}}{\sigma_{T}}\right)
$$

where $\mathrm{T}_{0}-$ «just-in-time» delivery time with probability $\mathrm{P}_{0}$;

$\mathrm{T}_{\mathrm{c}}, \sigma_{\mathrm{T}}-$ the mean and the root-mean-square deviation of the delivery time accordingly.

In the case of constraints, instead of dependence (6), one should use the simulation modeling.

Models of inventory management. The main difference of this group of models from the rest is that the calculated dependencies are based on stochastic stock consumption processes and their reaching of one (or two) limits states.

In table 3, there are presented systematically calculated failure models (models of probability of deficit) for the main inventory management strategies and different options of description of the stock consumption processes.

Table 6. Failure models for different inventory management strategies

\begin{tabular}{|c|c|c|}
\hline Strategy & Options & $\begin{array}{l}\text { Options of description of stock consumption } \\
\text { processes }\end{array}$ \\
\hline $\begin{array}{l}\text { With a fixed level (with } \\
\text { re-order point ROP) }\end{array}$ & $\begin{array}{l}\text { 1.Order quantity } \mathrm{S}_{3}=\text { const } \\
\text { 2.Order quantity } \mathrm{S}_{3} \neq \text { const (mini max) }\end{array}$ & \multirow{3}{*}{$\begin{array}{l}\text { 1. Deterministic: } \\
\text { - linear, nonlinear; } \\
\text { - initial state («focus» or «stochastic variable »). } \\
\text { 2. Stochastic processes: } \\
\text { - stable, unstable; } \\
\text { - with vigorous or gentle stirring; } \\
\text { - initial state (see item 1). } \\
\text { 3. Flows of «rare events» } \\
\text { 4. The above-mentioned processes with «pulse» } \\
\text { or «extreme» emissions. }\end{array}$} \\
\hline Periodic (T, S) & $\begin{array}{l}\text { 1. Periodic delivery: values of } \mathrm{T}_{0} \text { and } \mathrm{S}_{3} \text { are } \\
\text { constant. } \\
\text { 2. } \mathrm{T}_{0}=\text { const } \\
\mathrm{S}_{3}=\operatorname{var}\left(\text { up to } \mathrm{S}_{\max }\right)\end{array}$ & \\
\hline Combined & $\begin{array}{l}\text { 1. Order is placed when inventory level is less } \\
\text { than ROP or at } \mathrm{T}_{0} \text { moment of time } \\
\text { 2. Order is placed at } \mathrm{T}_{0} \text { moment of time if } \\
\text { inventory level is less than ROP }\end{array}$ & \\
\hline
\end{tabular}

Calculation dependencies to estimate the probability of occurrence of deficit are given in the papers (Ballou, 1999; Gertsbakh and Kordonsky, 1966; Lukinskiy et.al., 2012). 
The presented failure models allow evaluating the probability of failure-free performance when executing a number of logistics operations and functions. At the same time, a number of problems require further development associated with diversification of supplies, the relationship between events and running processes, their sequence and others.

\section{Approbation}

Approbation of the developed methodical approach has been carried out with the use of the data published in various sources and of the collected information on the indicators of reliability of logistics enterprises (transport companies, warehouses, etc.).

The most developed of all failure models to assess the reliability are those related to inventory management in warehouses in multilevel supply chains. On the one hand, this is due to the importance of the solution of the problem connected with deficit and excess inventories for enterprises; on the other hand, it can be explained by a deep theoretical study of inventory management tasks and cumulated experience of their practical solving. In addition, by its nature, the inventory management models are identical to the classical failure models in technical systems.

With regard to models of perfect order, the practice of calculations of key performance indicators (KPI), which became widespread because of the implementation of the balanced scorecard system in some enterprises, played a positive role in their development. In general, we can say that these models are efficient, and their further development requires changes and updates to data collection and analysis of primary data.

The model of selection of intermediaries and the JIT model also can be referred to quite successfully developed models. But they did not receive wide distribution because of the lack of relevant sections in the textbooks on logistics and supply chain management. For this reason, the probabilistic model of «supply and demand» is almost never used in the process of procurement and management of orders.

\section{Conclusion}

The complex of failure models to assess the reliability covers the major functional areas of logistics and includes key logistics functions and operations: procurement, orders management, transportation, inventory management, warehousing and materials handling. Revised and improved models allow calculation of the necessary reliability indices for the elements of supply chains, in other words, they allow actual assessment of the level of customer satisfaction.

Further development of the developed complex is connected with the identification of causes that are giving rise to failures during the execution of logistics operations that are related to the change in the parameters of material, information, financial, and particularly intellectual (human factor) flows. In this case, the opportunity to assess the reliability of supply chains, not only during re-engineering but also during the design of logistic systems, becomes real.

\section{References}

1. Ballou, R.N. (1999) Business logistics Management. New Jersey: Prentice-Hill International.

2. Blanchard, Benjamin S. (2004) Logistics Engineering and Management. USA: Pearson. Prentice Hall.

3. Christopher, M. (2004) Logictics and supply chain management. Harlow, UK: FT Prentice Hall.

4. Gertsbakh, B. and Kordonsky, K. (1966) Models of failures. Soviet radio.

5. Lukinskiy, V.S., Lukinskiy, V.V., Churilov, R. (2014) Problems of the supply chain reliability evaluation. Transport and telecommunication, 15(2), 214-222. DOI: 10.2478/ttj-2013-1018.

6. Lukinskiy, V.S., Lukinskiy, V.V., Malevich, J.V., Plastuniak, I.A., Pletneva, N.G. (2012) Models and methods of the logistics theory. St.Petersburg: SPbSUEE.

7. Sergeev, V.I. (2013) Supply Chain Management. Moscow: Uwrite.

8. Wentzel, Elena. (1969) Model for calculation of reliability indices (similar model). Moscow: Nauka.

9. Wolfgang, K. and Thorsten, B. (2006) Managing Risks in Supply Chains. How to Build Reliable Collaboration in Logistics. Berlin: Erich Schmidt Verlag.

10. Zaitzev, E.I. and Uvarov, S.A. (2012) Using indicators of Perfect order Fulfillment in the distribution logistics, Logistics and Supply Chain Management, 4(51), 16-22. 